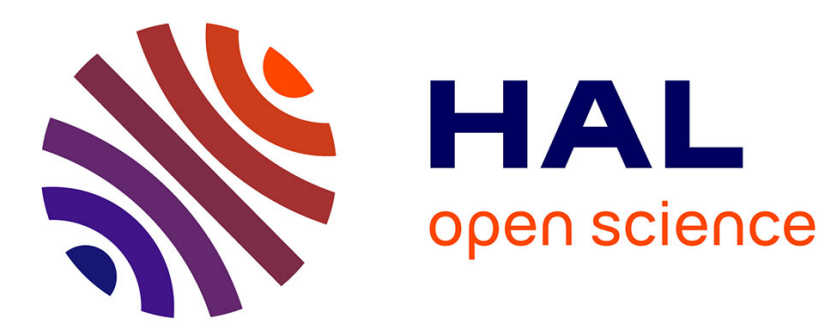

\title{
Effect of prestrain on ductility and toughness in a high-strength line pipe steel
}

\author{
Yazid Madi, Yasuhiro Shinohara, Jacques Besson
}

\section{To cite this version:}

Yazid Madi, Yasuhiro Shinohara, Jacques Besson. Effect of prestrain on ductility and toughness in a high-strength line pipe steel. International Journal of Fracture, 2020, 10.1007/s10704-020-00442-6 . hal-02636866

\section{HAL Id: hal-02636866 https://hal.science/hal-02636866}

Submitted on 27 May 2020

HAL is a multi-disciplinary open access archive for the deposit and dissemination of scientific research documents, whether they are published or not. The documents may come from teaching and research institutions in France or abroad, or from public or private research centers.
L'archive ouverte pluridisciplinaire HAL, est destinée au dépôt et à la diffusion de documents scientifiques de niveau recherche, publiés ou non, émanant des établissements d'enseignement et de recherche français ou étrangers, des laboratoires publics ou privés. 
See discussions, stats, and author profiles for this publication at: https://www.researchgate.net/publication/340655337

\section{Effect of prestrain on ductility and toughness in a high-strength line pipe} steel

Article in International Journal of Fracture · March 2020

DOI: 10.1007/s10704-020-00442-6

CITATIONS

3 authors, including:

(A) Yazid Madi

MINES ParisTech

42 PUBLICATIONS 266 CITATIONS

SEE PROFILE

Some of the authors of this publication are also working on these related projects:

Atlas+ View project

\section{READS}

78

Jacques Besson

MINES ParisTech

269 PUBLICATIONS 6,437 CITATIONS

SEE PROFILE 


\title{
Effect of prestrain on ductility and toughness in a high-strength line pipe steel
}

\author{
Yazid Madi $^{1,2}$ - Yasuhiro Shinohara ${ }^{1,3} \cdot$ Jacques \\ Besson $^{1}$
}

\begin{abstract}
Fracture properties of a mother plate for API grade X100 line pipe after pre-straining up to $6 \%$ are investigated using tensile notched bars and CT pre-cracked specimens. The material has an anisotropic plastic and damage behavior due to the thermomechanical control rolling process. Experiments evidence a decrease in both ductility and toughness for both rolling and long transverse direction with increasing prestrains. This effect is however more pronounced at low prestrain levels $(0 \rightarrow 2 \%)$ than at higher levels $(2 \rightarrow 4 \rightarrow 6 \%$ ). The modified GTN model proposed by Shinohara et al. (2016) is used to represent the database. A good agreement is obtained provided some damage model parameters are modified so as to obtain a slightly higher damage rate for the prestrained materials. This represents the fact that void growth tends to be faster for materials with a lower work hardening rate as evidenced by unit cell calculations. In addition, stress/strain distributions in test specimens are modified for reduced hardening so that stress triaxiality is increased at failure initiation points. This further lowers measured mechanical properties.
\end{abstract}

Keywords Prestrain · Ductile failure · Plastic anisotropy · Failure anisotropy · API high grades steel line pipes

\section{Introduction}

Demand for development of natural resources becomes strong as consumption of energy is increasing around the world. Natural gas is the cleanest of all fossil fuels. Generally, gas is transported from the product to consumer area by pipeline. Application of higher strength steel (HSLA) line pipes leads to many benefits in a gas pipeline project, such less steel required lower transportation costs and lower laying costs. X90, X100 and X120 high grade steel line pipes were standardized as ISO3183 and API 5L. X100 and X120 steel have been already used for small-scale laying tests and operational trails (Asahi et al., 2009).

Generally, line pipes have been required to have high ductile crack initiation and tearing resistance to prevent of ductile crack propagation along the longitudinal direction of the pipe body in the case of an accident occurring during operation. In addition, high strength line pipes are subjected to environmental loads from offshore ice, discontinuous permafrost

\footnotetext{
${ }^{1}$ MINES ParisTech, PSL Research University, Centre des Matériaux, CNRS UMR 7633, Evry, France .

${ }^{2}$ Ermess, EPF-École d'ingénieurs, Sceaux, France

${ }^{3}$ Nippon Steel \& Sumitomo Metal Corporation .
} 
or seismic activity. This has recently led to the development of strain-based design which allows the plastic deformation of the pipe to be taken into account (Lillig, 2008). However, even if the pipe is able to withstand the load, it remains important to quantify the impact of plastic strain on both ductility and toughness. A similar problem is encountered in the case of large pipes processed using UOE forming (Yoo et al., 2011) as the properties of the mother plate may significantly differs from those of the final product. These problems are particularly important in the case of (very) high strength steels such as API X100 or X120 which show limited hardening capability with a uniform elongation between 6 and $8 \%$ in the mother plate (Tsuru et al., 2008; Shinohara et al., 2008, 2010). In addition these materials often exhibit an anisotropic plastic behavior due to crystallographic texture of the mother plate that is sharpened through thermo-mechanical control process (TMCP) in a heavy plate mill. In this study, the effect of tensile pre-strain on both ductility and toughness will be investigated in the case of an API X100 line pipe steel.

The first effect of pre-straining is a decrease of the uniform elongation, strain to failure and reduction of area and an increase of the yield stress and tensile strength (UTS). The uniform elongation as well as the strain at UTS are reduced by about the level of pre-strain as shown for HSLA (Baek et al., 2010; Sivaprasad et al., 2000; Shinohara et al., 2010). A similar effect was demonstrated in the case of a nuclear pressure vessel steel (El-Fadaly et al., 1995). In addition is was shown that compressive deformation has a lower impact on the tensile properties, a trend which can be associated with the Bauschinger effect.

Some experimental tests and numerical analysis have been conducted to study the effect of prestrain on ductile fracture (Sivaprasad et al., 2000; Enami, 2005a,b; Baek et al., 2010). In HSLA steels, ductile fracture toughness was reported to remain unchanged up to $2 \%$ prestrain whereas is was deteriorated with prestrain beyond $2 \%$ (Sivaprasad et al., 2000). In the case of conventional structural steel, compressive prestrain up to $30 \%$ led to cleavage cracking and reduced ductility significantly (Enami, 2005b). In API 5L X65 line pipes, prestrain up to $5 \%$ had little effect on ductile fracture toughness of specimens loaded along the longitudinal direction while Charpy impact energy along the transverse direction considerably decreased with increasing the prestrain level (Baek et al., 2010). Decrease of toughness and Charpy impact energy was larger for a prestrain level of $10 \%$. In the case of carbon steel plates, Kamaya (2012) evidenced a reduction of ductility with increasing prestrain (up to 20\%) using axisymmetric round notched bars. $J-\mathrm{R}$ curves also evidenced a strong decrease of resistance with increasing prestrain. Brittle fracture was observed on CT specimens in the case of highly deformed materials. Similar trends observed on notched bars are also reported in (Basu and Benzerga, 2015) and analyzed in (Thomas et al., 2016). These trends are somehow supported by the micromechanical analysis of the effect of prestraining on void coalescence proposed by Zhang and Skallerud (2010) which indicates that the strain at coalescence is reduced by prestraining. In (Chae et al., 2000) the effect of pre-straining at high triaxiality on the residual ductility at low triaxiality is experimentally studied and results interpreted using finite element simulation at the microstructure level. The effect of prestraining was also studied in (Alinaghian et al., 2014) using mesoscopic voids introduced by laser machining. A clear reduction of ductility was observed with increasing pre-straining which was reproduced correctly by simulations in which the machined voids are represented.

The effect of prestraining was also investigated in cases where a pre-existing crack exists. Eikrem et al. (2007) showed, based on a numerical analysis, that prestraining leads to a higher crack tip constraint which increases crack tip stresses. In (Eikrem et al., 2008) it is shown that fracture resistance is reduced due to the accumulation of ductile damage during loading cycles before final failure. A similar approach was applied to welded joints 
Song et al. (2017). However experimental investigation carried out by Tkaczyk et al. (2011) using cross weld SENT specimens (X70 base metal) showed no effect of prestrain on crack growth resistance curves.

In this study a grade X100 line pipe steels was tested in the as-received state and in several prestrained states (2, 4 and 6\%) to evaluate the effect of prestrain on both ductility and toughness. The prestrain level is limited to the strain at the onset of necking. Test specimens include tensile tests on smooth and notched bars and tests on precracked CT specimens (section 2). Experimental results for the various prestrained states and two loading directions (rolling and long transverse) are presented in section 3. The model developed in (Shinohara et al., 2016) to represent plasticity and ductile damage and accounting for anisotropy is briefly recalled in section 4 . This model is then used to carry out finite element simulations to model the effect of prestraining on both ductility (notched bars) and toughness (CT specimens). The origin of the decrease in ductility and toughness with increasing prestrain levels is finally discussed in section 6 based on unit cell simulations and additional finite element simulations.

\section{Material and experimental procedures}

The material used is a high strength steel plate with a thickness of $16 \mathrm{~mm}$ and employed in the manufacture of line pipes produced in a commercial heavy plate mill. The chemical composition is shown in Tab. 1. The plate was made through TMCP and accelerated cooling process in the mill. The material has a dual phase microstructure consisting of fine polygonal ferrite and bainite structure.

Table 1 Chemical composition of the used steel (weight \%).

\begin{tabular}{ccccccc}
\hline $\mathrm{C}$ & $\mathrm{Si}$ & $\mathrm{Mn}$ & $\mathrm{P}$ & $\mathrm{S}$ & $\mathrm{Ti}$ & $\mathrm{N}$ \\
\hline 0.051 & 0.20 & 1.95 & 0.007 & 0.0015 & 0.012 & 0.004 \\
\hline Others: $\mathrm{Ni}, \mathrm{Cr}, \mathrm{Cu}, \mathrm{Nb}$.
\end{tabular}

The steel has anisotropic mechanical properties due to development of a specific crystallographic texture by TMCP ; hence it is important to keep track of the material principal axes. In the following, the longitudinal direction, which corresponds to the rolling direction, is referred to as $\mathrm{L}$; the transverse direction is referred to as $\mathrm{T}$, the diagonal direction in the $\mathrm{L}-\mathrm{T}$ plane is referred to as $\mathrm{D}$ and the short transverse (thickness) direction is referred to as $\mathrm{S}$.

Prestrain tests were first conducted, using a $4000 \mathrm{kN}$ tensile testing machine. Large flat tensile specimens (see Fig. 1) were machined so that a $200 \mathrm{~mm} \times 100 \mathrm{~mm}$ zone, where applied strain is uniform, could be produced at the center of the specimen. Strain gauges were glued on the surface of tested specimens to check the actual prestrain level. The level of prestraining was up to $6 \%$. Prestrain was performed along the $\mathrm{T}$ direction which corresponds to the main deformation direction during pipe forming.

A comprehensive characterization of the mechanical properties of the steel was conducted along three different directions (L, T and D) using several types of tensile test specimens. The used geometries are presented in Fig. 2. All tests were performed at room temperature on a servo-hydraulic testing machine for the as-received and prestrained 


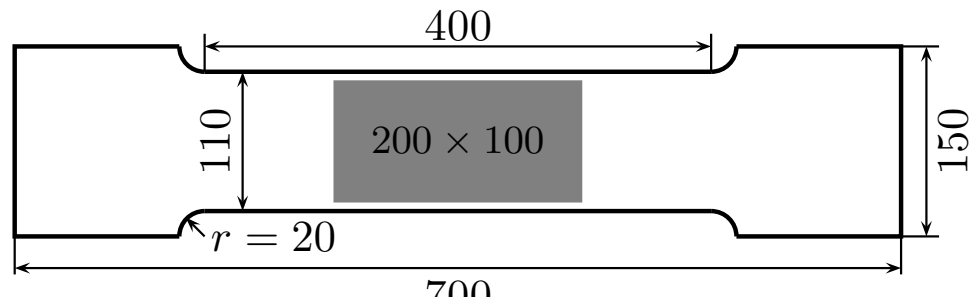

700

Fig. 1 Large tensile specimen for prestraining (dimensions in $\mathrm{mm}$ ). The gray area indicates the zone where prestrain is homogeneous.

materials. Test specimens include smooth tensile bars (ST) and axisymmetric notched bars with various notch radii $\left(\mathrm{NT}_{\chi}\right)$. Notches are used to characterize rupture (see e.g. (Mackenzie et al., 1977)), as they allow inducing stresses in directions perpendicular to the main loading direction (in particular along the $\mathrm{S}$ direction) and consequently allow to test multi-axial stress states using a simple experimental setup.

In the case of ST specimens, strain was measured using an extensometer with an initial gauge length of $L_{0}=9 \mathrm{~mm}$. $\Delta L$ denotes the gauge length variation. The imposed strain rate was: $\Delta \dot{L} / L_{0}=5 \cdot 10^{-4} \mathrm{~s}^{-1}$. The diameter reduction $\left(\Delta \Phi_{\mathrm{S}}\right)$ in the minimum cross section was measured along the $\mathrm{S}$ direction for which deformation is maximum. In the case of $\mathrm{NT}_{\chi}$ specimens, the machine cross-head speed was selected so as to obtain a measured strain rate approximately equal to $5 \cdot 10^{-4} \mathrm{~s}^{-1}$. In the following $F$ denotes the force, $S_{0}$ the initial specimen minimum cross section, $\Phi_{0}$ the initial specimen minimum diameter.

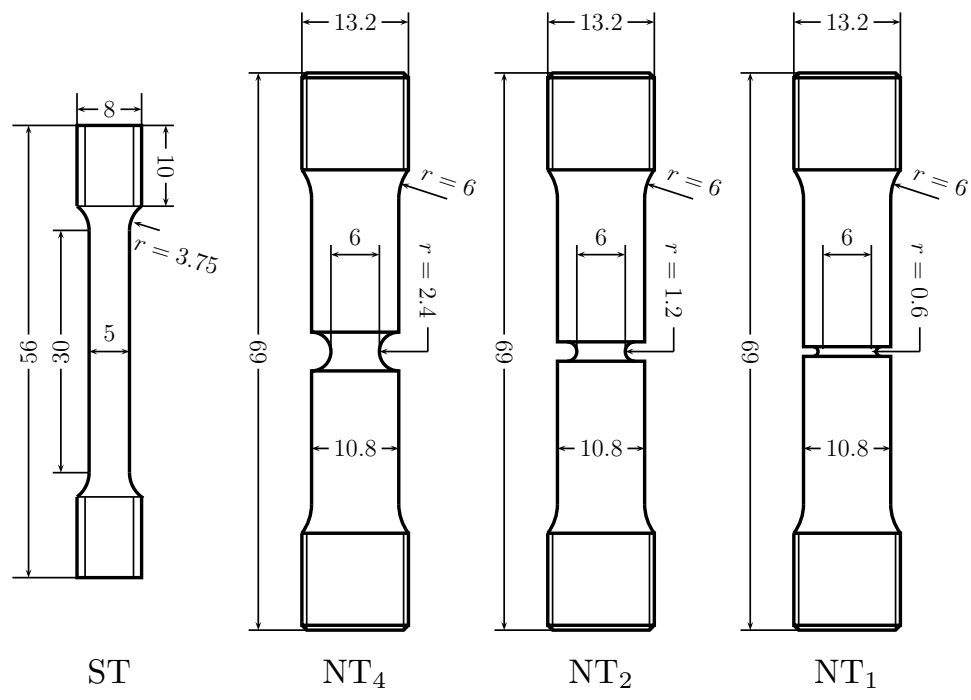

Fig. 2 Test specimens: smooth tensile bar, axisymmetric notched bars.

For determination of the ductile tearing resistance of the steel, compact tensile (CT) were used. The thickness, $B$, was $12.5 \mathrm{~mm}$. The specimen width is $W=2 B=25 \mathrm{~mm}$. 
Specimens were pre-cracked in fatigue so that a total initial crack length $\left(a_{0}\right)$ of all specimens could be between $0.51 \mathrm{~W}$ and $0.62 \mathrm{~W}$. All other dimensions correspond to the ASTM-1820 standard (ASTM-1820, 2008). However the specimens were not sidegrooved. The $J-\Delta a$ resistance curve was determined usingthe multi-specimen technique for as received and prestrained materials. The fracture toughness test was conducted under displacement control at room temperature. The displacement rate was $1 \mathrm{~mm} / \mathrm{min}$. Specimens were tested for two loading configurations: T- $\mathrm{L}$ for which loading is applied in the $\mathrm{T}$ direction whereas the crack propagates along the $\mathrm{L}$ direction and $\mathrm{L}-\mathrm{T}$ for which loading and cracking directions are permuted. Force and displacement were simultaneously recorded during the test, in order to calculate $J$ as follows:

$$
J=J_{e l}+J_{p l}
$$

where: $J_{e l}=$ elastic component of $J$, and $J_{p l}=$ plastic component of $J . J_{e l}$ can be calculated from the following equation:

$$
J_{e l}=\frac{K^{2}\left(1-\nu^{2}\right)}{E}
$$

where: $K$ is the stress-intensity factor computed for the initial crack length $a_{0} . J_{p l}$ can be calculated from the following equation:

$$
J_{p l}=\frac{\eta A_{p l}}{B\left(W-a_{0}\right)}
$$

where: $A_{p l}=$ plastic area under the load versus load-line displacement and $\eta=2+$ $0.522(1-a / W)$ following the ASTM-E1820 standard. Ductile crack extension, $\Delta a$, was directly determined on a fracture surface of the tested specimens, which were broken at liquid nitrogen temperature after unloading, by means of the 9-point averaging method.

\section{Experimental results}

\subsection{Tensile tests}

Nominal stress-strain curves of smooth bar tests loaded along different directions are shown in Fig. 3 for the as-received and prestrained materials. Curves are plotted up to the ultimate stress point, which corresponds with the onset of necking. Flow stress in all directions increases with increasing prestrain level. Prestraining causes immediate appearance of necking in the $\mathrm{T}$ direction when prestrain levels is over $4 \%$. The prestrained material has no remaining hardening capability along the $\mathrm{T}$ direction. Some hardening capability is retained along $\mathrm{L}$ and $\mathrm{D}$ loading directions for all prestrain levels. These effects have been explained by the presence of kinematic hardening (Shinohara et al., 2010). In addition, plastic deformation of the initially circular cross section depends on the loading direction. Fracture surfaces of the smooth tensile bar specimens are shown in Fig. 3. The photographs indicate plastic anisotropy in $\mathrm{L}$ and $\mathrm{T}$ directions. In that case plastic deformation is larger along the $\mathrm{S}$ direction. Plastic deformation appears to be isotropic in the case of $\mathrm{D}$ loading. 


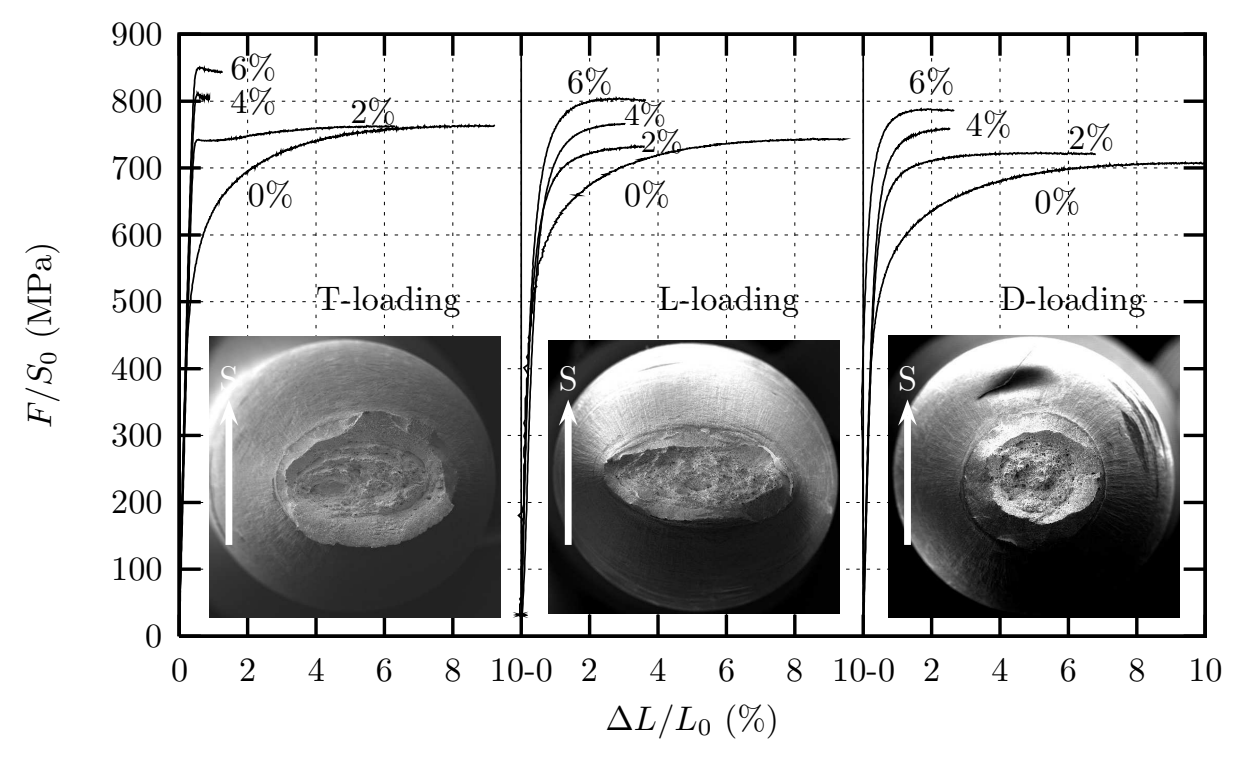

Fig. 3 Nominal stress $\left(F / S_{0}\right)$ as a function of strain for T, $\mathrm{L}$ and $\mathrm{D}$ loading directions for the different prestrain levels.

\subsection{Tests on notched tensile bars}

Tests on notched tensile bars are used to characterize fracture initiation which corresponds to a sharp load drop on the Force-Diameter reduction curves (see e.g. arrow in fig. 4). The diameter reduction at fracture initiation $\left(\Delta \Phi_{S} /\left.\Phi_{0}\right|_{c}\right)$ will be referred to as "ductility" in the following.

As stress triaxiality is maximum at the center of the specimens' minimum cross section, fracture is always initiated from that location. This was verified by interrupting some tests just after the onset of load drop. Samples are subsequently broken in liquid nitrogen. Fractography then reveals some ductile dimples located at the center of the broken cross section. A total of 24 configurations have been tested corresponding to 3 specimens types $\left(\mathrm{NT}_{4}, \mathrm{NT}_{2}\right.$ and $\left.\mathrm{NT}_{1}\right), 2$ orientations ( $\mathrm{T}$ and $\left.\mathrm{L}\right)$ and 4 prestrain levels $(0,2,4$ and $6 \%)$. For each configuration, tests were repeated at least 2 times.

Effect of stress triaxiality: The effect of stress triaxiality is studied by varying the specimens' notch radii as in numerous previous studies. Fig. 4 shows the experimental normalized force $\left(F / S_{0}\right)$ vs. relative diameter reduction $\left(\Delta \Phi_{\mathrm{S}} / \Phi_{0}\right)$ curves for L loading and $2 \%$ prestrain for $\mathrm{NT}_{4}, \mathrm{NT}_{2}$ and $\mathrm{NT}_{1}$ specimens. The load increases with decreasing notch radius indicating that the axial stresses are increased due to a higher stress triaxiality developing inside the specimen. It is shown that ductility, defined as the onset of failure corresponding to the sharp load decrease, is smaller for $\mathrm{NT}_{2}$ and $\mathrm{NT}_{1}$ specimens compared to $\mathrm{NT}_{4}$ samples. Ductilities for $\mathrm{NT}_{2}$ and $\mathrm{NT}_{1}$ specimens are very close. However the load drop is faster for $\mathrm{NT}_{1}$ specimens. These trends are observed for all testing configurations (loading direction and prestrain level). 


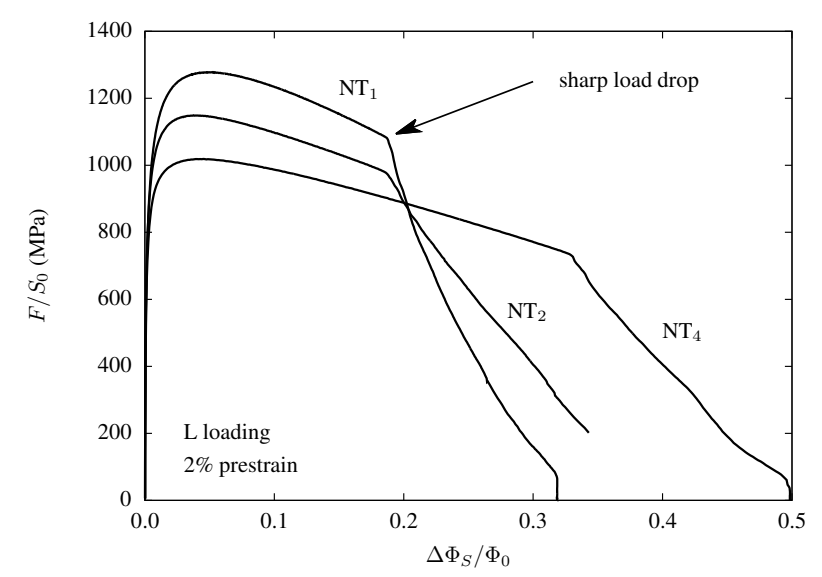

Fig. 4 Experimental normalized force $\left(F / S_{0}\right)$ vs. relative diameter reduction $\left(\Delta \Phi_{\mathrm{S}} / \Phi_{0}\right)$ curves for $\mathrm{L}$ loading and $2 \%$ prestrain for $\mathrm{NT}_{4}, \mathrm{NT}_{2}$ and $\mathrm{NT}_{1}$ specimens.

Effect of loading direction - Anisotropic ductility: The effect of loading direction on ductility is exemplified in fig. 5 in the case of $\mathrm{NT}_{2}$ and $\mathrm{NT}_{1}$ specimens for a prestrain level of $4 \%$. For both specimen types, ductility is always smaller for specimens tested along the $\mathrm{T}$ direction. This trend is confirmed for all specimen types and prestrain levels. It is also confirmed that (i) ductility of $\mathrm{NT}_{2}$ and $\mathrm{NT}_{1}$ specimens are close for a given test configuration, (ii) load drop after crack initiation is faster for $\mathrm{NT}_{1}$ specimens.

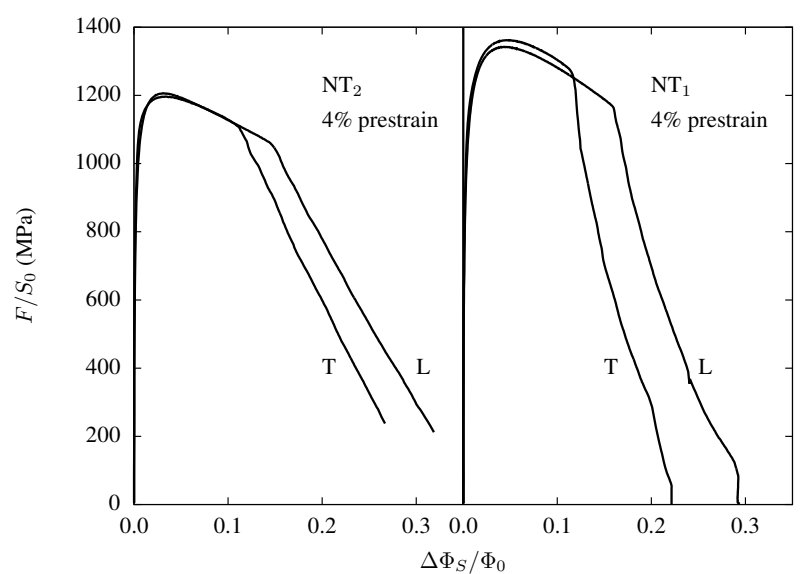

Fig. 5 Experimental normalized force $\left(F / S_{0}\right)$ vs. relative diameter reduction $\left(\Delta \Phi_{\mathrm{S}} / \Phi_{0}\right)$ curves for $4 \%$ prestrain for $\mathrm{NT}_{2}$ and $\mathrm{NT}_{1}$ specimens tested along $\mathrm{L}$ and $\mathrm{T}$ directions.

Effect of prestrain: The effect of prestrain is illustrated in the case of $\mathrm{NT}_{2}$ specimens for $\mathrm{T}$ and $\mathrm{L}$ loading in fig. 6. Increasing prestrain leads to an increase of the maximum load due to hardening and a decrease of ductility. This decrease is more important for a prestrain of $2 \%$. Prestrain levels of 4 or $6 \%$ appear to have a similar effect on ductility. The slope 
of the sharp load drop does not appear to be affected by prestrain. These trends are also obtained for other specimen types and loading directions. Averaged ductilities obtained for all specimens, directions and prestrain levels are gathered in fig. 7. A decrease of ductility is observed in all cases. As mentioned in the case of fig. 6, ductility decrease is almost similar for $4 \%$ and $6 \%$ prestrain. Ductility drop also appears to be more important for $\mathrm{T}$ loading than for L loading.

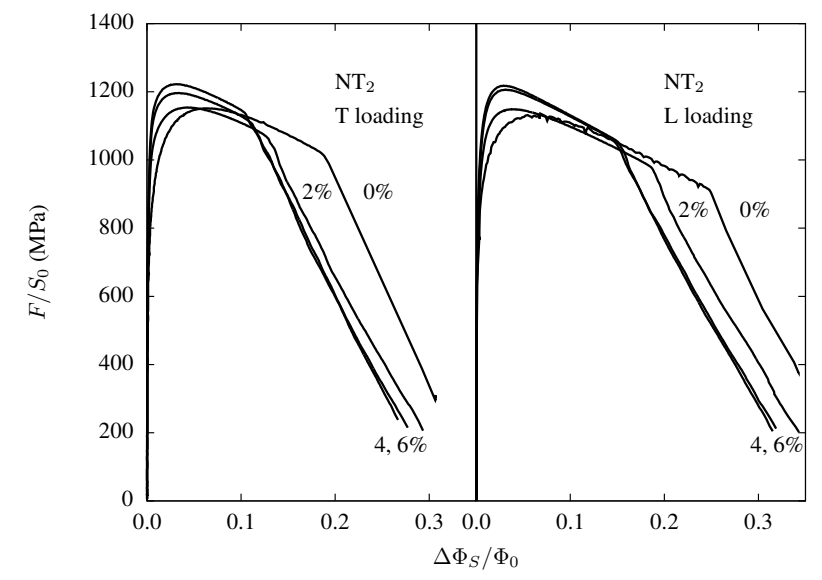

Fig. 6 Experimental normalized force $\left(F / S_{0}\right)$ vs. relative diameter reduction $\left(\Delta \Phi_{\mathrm{S}} / \Phi_{0}\right)$ curves for $\mathrm{NT}_{2}$ specimens tested along $\mathrm{L}$ and $\mathrm{T}$ directions for various prestrain levels.

The change in area reduction $Z=\left(S_{0}-S_{R}\right) / S_{0}$ (where $S_{R}$ is the cross section after failure) is plotted in fig. 8 also including results on smooth tensile bars (ST). Previous trends are confirmed. $Z$ for $\mathrm{T}$ loading is smaller than for $\mathrm{L}$ loading and decreases with increasing prestrain. Note that the value of $Z$ is smaller for $\mathrm{NT}_{1}$ specimens than for $\mathrm{NT}_{2}$ specimens whereas ductilities are close.

\subsection{Tests on CT specimens}

R-curves for both $\mathrm{L}-\mathrm{T}$ and $\mathrm{T}-\mathrm{L}$ configurations for all prestrain levels are shown in fig. 9-a and 9-b respectively. For each case, a linear regression is used to fit a $J-\Delta a$ curve as $J=J_{0}+T \Delta a$. $J_{0}$ can be interpreted as the $J$ value at crack initiation. $T$ corresponds to the tearing modulus $d J / d a$. It is noticed that the material is tougher when tested in $\mathrm{L}-\mathrm{T}$ configuration compared to the T-L configuration. This is true for the as-received material, as already described in (Shinohara et al., 2016), but also for the prestrained materials. For both testing configurations, prestrain causes a decrease of $J$ values but leaves the tearing modulus $(T)$ almost unchanged. Computed values for $J_{0}$ and $T$ are gathered in tab. 2 . The effect of prestraining tends to rapidly saturate for prestrain levels above $2 \%$ as in the case of $\mathrm{NT}_{\chi}$ specimens. 


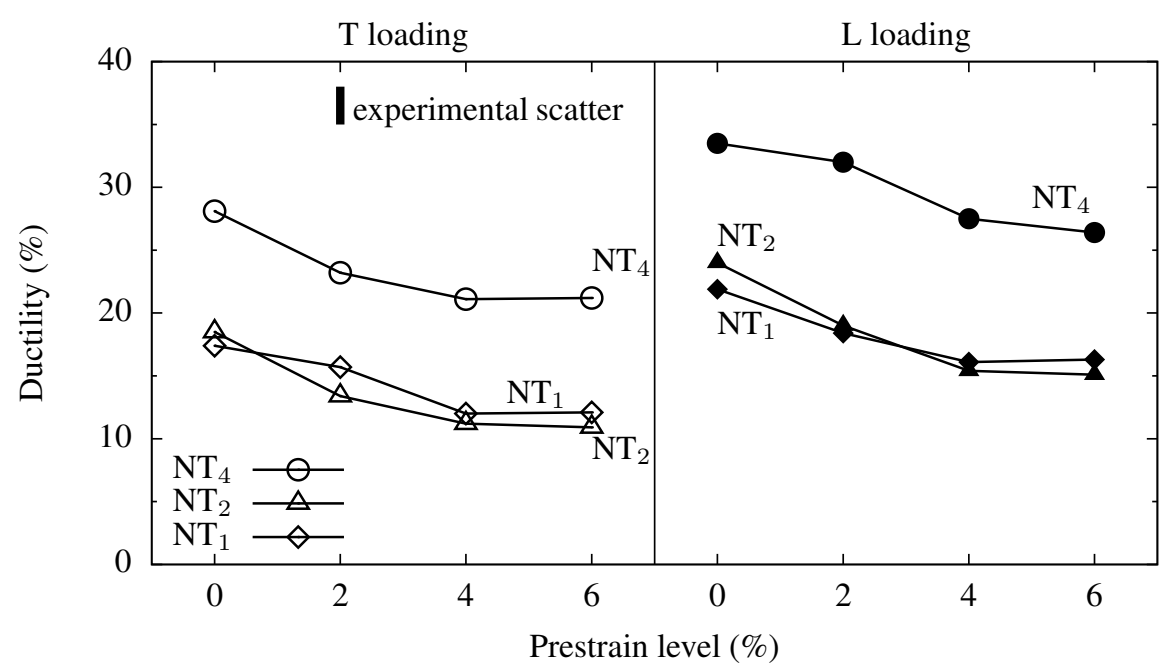

Fig. 7 Experimental ductility $\left(\Delta \Phi_{S} /\left.\Phi_{0}\right|_{c}\right.$ ) as a function of prestrain. T-loading (open symbols) and Lloading (closed symbols).

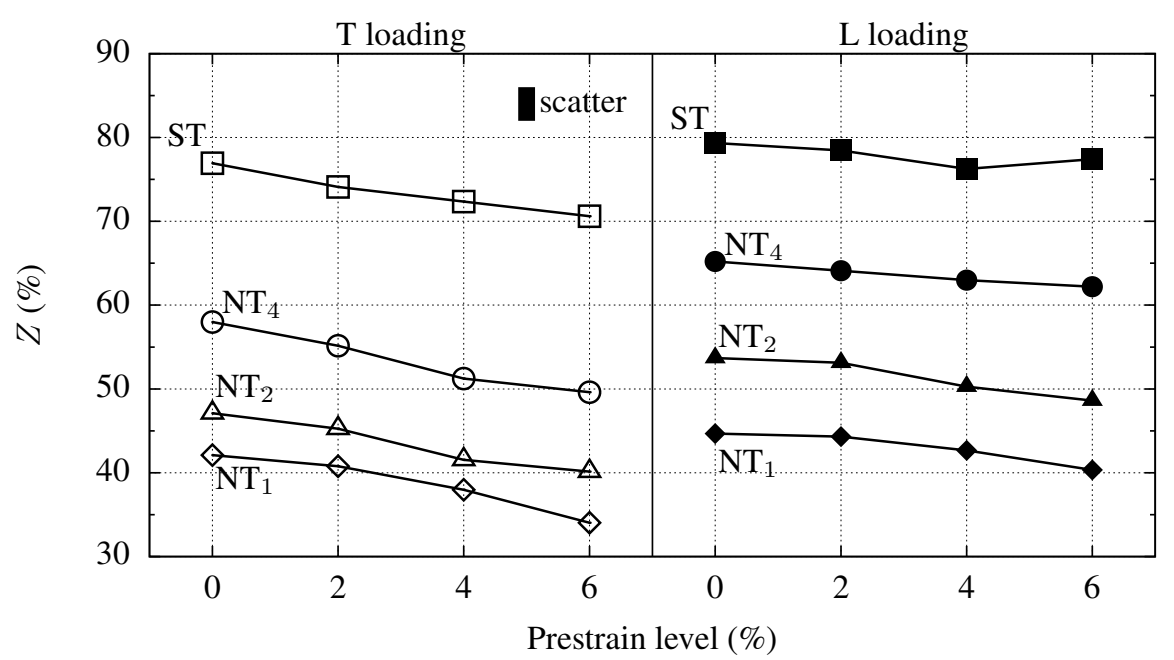

Fig. 8 Experimental area reduction $(Z)$ as a function of prestrain. T-loading (open symbols) and L-loading (closed symbols).

\subsection{Fractography}

Fracture surfaces of all fractured specimens were observed using Scanning Electron Microscopy (SEM). As already reported in (Shinohara et al., 2016) fracture surfaces mainly consist of relatively large primary dimple initiated on sulfides $(\mathrm{CaS})$ or oxides. Smaller dimples can also be seen; their amount increases as the stress triaxiality ratio is decreased 


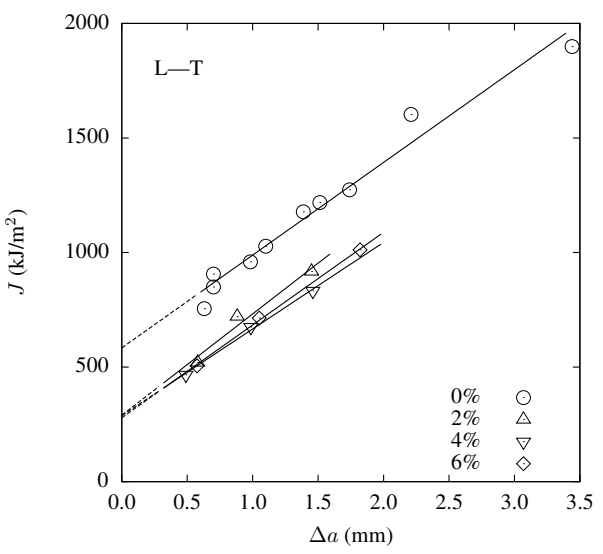

(a) $\mathrm{L}-\mathrm{T}$ loading

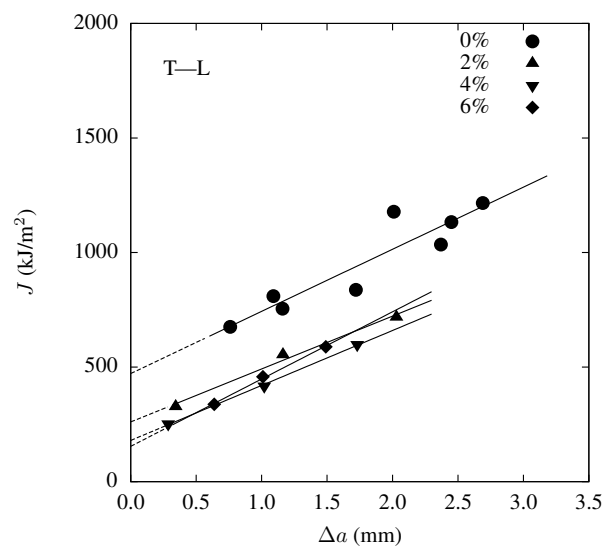

(b) T-L loading

Fig. $9 J-\Delta a$ curves for all prestrain levels: (a) $\mathrm{L}-\mathrm{T}$ configuration, (b) $\mathrm{T}-\mathrm{L}$ configuration. Solid lines correspond to the fit of the experimental data as $J=J_{0}+T \Delta a$ for each testing condition (configuration and prestrain level).

\begin{tabular}{|c|c|c|}
\hline & as-received & prestrained $(2,4$ and $6 \%)$ \\
\hline \multicolumn{3}{|l|}{$\mathrm{T}-\mathrm{L}$ loading } \\
\hline$J_{0}\left(\mathrm{~kJ} / \mathrm{m}^{2}\right)$ & 472 & 198 \\
\hline$T(\mathrm{MPa})$ & 271 & 254 \\
\hline$T(\mathrm{MPa})$ & \multicolumn{2}{|r|}{259} \\
\hline \multicolumn{3}{|l|}{$\mathrm{L}-\mathrm{T}$ loading } \\
\hline$J_{0}\left(\mathrm{~kJ} / \mathrm{m}^{2}\right)$ & 583 & 285 \\
\hline$T(\mathrm{MPa})$ & 405 & 408 \\
\hline$T(\mathrm{MPa})$ & \multicolumn{2}{|r|}{407} \\
\hline
\end{tabular}

Table 2 Values of $J$ at initiation $\left(J_{0}\right)$ and tearing modulus $T$ for the as-received and prestrained materials for $\mathrm{T}-\mathrm{L}$ and $\mathrm{L}-\mathrm{T}$ loading. Average values are given for the prestrained materials as individual values are very close. Average values for all materials (as-received and prestrain) are also indicated for the tearing modulus which is hardly affected by prestrain.

as already observed in (Tanguy et al., 2008). Smaller dimples are initiated on iron carbides $\left(\mathrm{Fe}_{3} \mathrm{C}\right)$. It was not possible to find the origin of fracture anisotropy which was attributed to an anisotropic distribution of primary inclusions (Shinohara et al., 2016). Similar observations were conducted comparing as-received and prestrained materials for similar testing conditions (i.e. same specimen type and same orientation). An example of such a comparison is shown in fig. 10 where fracture surfaces at the center of the specimen (i.e. at the fracture initiation location) for $\mathrm{NT}_{4}$ specimens tested along the $\mathrm{T}$ direction are presented. Fig. 10-a shows the as-received material whereas fig. 10-b shows the $6 \%$ prestrained material. Fracture surfaces are very similar which evidences that failure mechanisms are similar. Similar conclusions were drawn from the comparison of other specimen types $\left(\mathrm{NT}_{\chi}\right.$ and $\mathrm{CT}$ ). 


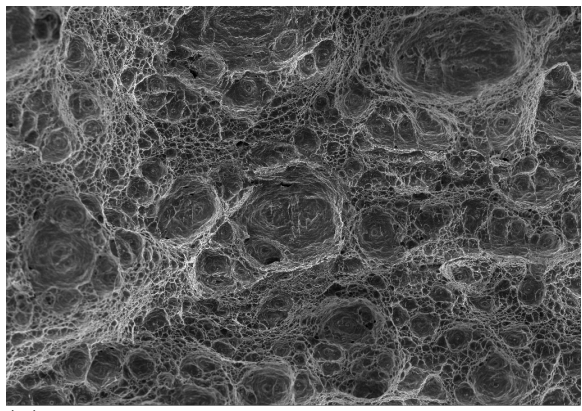

(a) as received

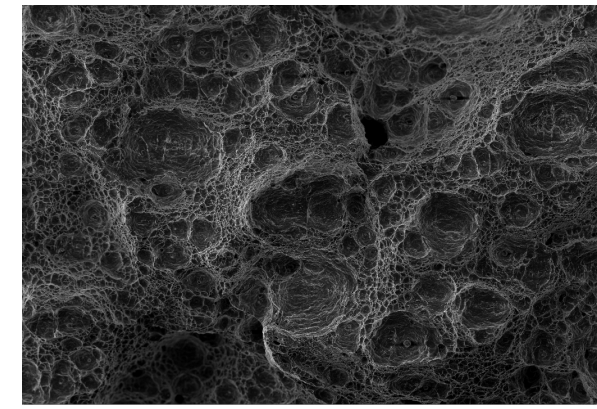

$100 \mu \mathrm{m}$ (b) $6 \%$ prestrain

Fig. 10 Fractography of $\mathrm{NT}_{4}$ specimens for the as-received material (a) and $6 \%$ prestrained material (b). In both cases, the fracture surface mainly consists in primary dimples ; secondary dimples can also be observed.

\section{Models for plasticity and ductile damage}

In order to analyze the experimental database and propose explanations for the effect of prestrain on ductility and toughness, it is necessary to carry out a detailed Finite Element (FE) analysis of the various tests. It is therefore necessary to describe anisotropic plasticity and ductile damage. Models used in this study are briefly recalled below as they were already presented in previous works (Tanguy et al., 2008; Shinohara et al., 2016; Bron and Besson, 2004; Morgeneyer et al., 2009).

\subsection{Model for anisotropic plasticity}

The model used in this study to describe plastic anisotropy was initially developed in the case of aluminum alloys (Bron and Besson, 2004) as an extension of existing models (Barlat et al., 1991; Karafillis and Boyce, 1993). It was applied to describe the plastic behavior of pipe materials in (Tanguy et al., 2008; Shinohara et al., 2012, 2016) and aluminum alloys (Bron and Besson, 2004; Zhang et al., 2014; Morgeneyer et al., 2009). Compared to the well known Hill plasticity model (Hill, 1950), the model introduces more material parameters which allow the description of both stress and strain anisotropy which is often difficult with Hill's model (Rivalin et al., 2000).

The model is based on the definition of a anisotropic scalar stress measure, $\sigma_{E}$ as:

$$
\sigma_{E}=\left(\alpha_{1} \sigma_{E 1}^{a}+\alpha_{2} \sigma_{E 2}^{a}\right)^{1 / a}
$$

Each scalar stress, $\sigma_{E k=1,2}$, is defined using two modified stress deviators: $\underline{s}_{k}=\underline{\underline{L}}_{k}: \underline{\sigma}$ where $\underline{\sigma}$ is the Cauchy stress tensor. $\underline{\underline{L}}_{k}$ are two fourth order tensors (linear transformation tensors following Barlat et al. (2005)). The eigenvalues of $\underline{s}_{k=1,2}\left(S_{k}^{1} \geq S_{k}^{2} \geq S_{k}^{3}\right)$ are then used to compute $\sigma_{E k=1,2}$ as:

$$
\begin{aligned}
& \sigma_{E 1}=\left(\frac{1}{2}\left(\left|S_{1}^{2}-S_{1}^{3}\right|^{a}+\left|S_{1}^{3}-S_{1}^{1}\right|^{a}+\left|S_{1}^{1}-S_{1}^{2}\right|^{a}\right)\right)^{1 / a} \\
& \sigma_{E 2}=\left(\frac{3^{a}}{2^{a}+2}\left(\left|S_{2}^{1}\right|^{a}+\left|S_{2}^{2}\right|^{a}+\left|S_{2}^{3}\right|^{a}\right)\right)^{1 / a}
\end{aligned}
$$


The scalar stress measure, $\sigma_{E}$, is then used to define a yield surface:

$$
\phi=\sigma_{E}-\sigma_{F}(p)
$$

where $\sigma_{F}(p)$ is the flow stress and $p$ is effective cumulated plastic strain consistent with the yield surface. Normality is assumed and the cumulated plastic strain rate is expressed using a simple Norton flow rule to represent strain rate sensitivity as: $\dot{p}=\dot{\varepsilon}_{0}\left(\phi / \sigma_{0}\right)^{n}$.

Model parameters that need to be adjusted are therefore $\alpha_{1}\left(\alpha_{2}=1-\alpha_{1}\right), c_{k}^{i}(k=1,2$ and $i=\mathrm{TT} \ldots \mathrm{ST}), a, b_{1}$ and $b_{2}$. In the following the model was simplified assuming $a=b_{1}=b_{2}$. The parameter adjustment is carried out according to previous work (Bron and Besson, 2004). Tensile tests along L, T and D directions as well as all tests on notched bars with different minimum radii are considered when building the cost function. In the case of tensile smooth bars, force-axial displacement curves are used together with Lankford coefficients. They are defined as $\mathcal{L}_{\|}=\varepsilon_{\perp}^{p} / \varepsilon_{\mathrm{S}}^{p}$ considering true plastic strains where $\|$ corresponds to the loading direction and $\perp$ to the direction perpendicular to both the loading and $\mathrm{S}$ directions. $\varepsilon_{\perp}^{p}$ is computed assuming plastic incompressibility. Lankford coefficients are computed for an axial plastic strain between 1 and 6\% (i.e. before the onset of necking). The following values were obtained: $\mathcal{L}_{\mathrm{L}}=0.34, \mathcal{L}_{\mathrm{T}}=0.49$ and $\mathcal{L}_{\mathrm{D}}=1.00$. Additional tests were conducted along the $\mathrm{T}$ direction at different strain rates $\left(5.10^{-3} \mathrm{~s}^{-1}\right.$ and $5.10^{-2} \mathrm{~s}^{-1}$ ) to characterize strain rate sensitivity. In the case of notched bars, forcediameter reduction curves are used. Diameter reduction is measured along the $\mathrm{S}$ direction. Coefficients are given in (Shinohara et al., 2016).

\subsection{Model for ductile damage}

The model to describe ductile damage is a phenomenological extension of the well-known GTN model (Tvergaard and Needleman, 1984) which is modified to account for plastic anisotropy as well as ductility anisotropy. The model has already been used in (Morgeneyer et al., 2009; Shinohara et al., 2016). Following Besson et al. (2001), an effective stress measure accounting for damage, $\sigma_{*}$, is implicitly defined by the following equation which is solved for a given stress tensor and a given damage level:

$$
\frac{\sigma_{E}^{2}}{\sigma_{*}^{2}}+2 q_{1} f_{*} \cosh \left(\frac{1}{2} \frac{\alpha_{\mathrm{T}} \sigma_{\mathrm{TT}}+\alpha_{\mathrm{L}} \sigma_{\mathrm{LL}}+\alpha_{\mathrm{S}} \sigma_{\mathrm{SS}}}{\sigma_{*}}\right)-1-q_{1}^{2} f_{*}^{2} \equiv 0
$$

$\alpha_{\mathrm{T}}, \alpha_{\mathrm{L}}$ and $\alpha_{\mathrm{S}}$ are model coefficients used to represent failure anisotropy by introducing a weighted average of the stresses along the sheet principal directions which is used in lieu of the trace of the stress tensor in the GTN model. In (Shinohara et al., 2016) another model was also proposed to represent failure anisotropy. This model is a multi-surface model describing both void growth (GTN model) and coalescence by internal necking (Thomason, 1985b,a; Pardoen and Hutchinson, 2000; Besson, 2009). It has a stronger micromechanical foundation than the model used in this study. However, is it computationally less efficient so $=$ the more phenomenological version was used here. As shown in (Shinohara et al., 2016) both models lead to very similar results.

Damage corresponds to the void volume fraction, $f . f_{*}$ is a function of the porosity introduced in (Tvergaard and Needleman, 1984) to simply model failure by void coalescence. It is expressed as:

$$
f_{*}= \begin{cases}f & \text { if } f \leq f_{c} \\ f_{c}+\delta\left(f-f_{c}\right) & \text { otherwise }\end{cases}
$$


where $f_{c}$ is the porosity at which void coalescence starts. $\delta>1$ represents damage acceleration due to coalescence. Failure of a material point occurs when $f_{*}=1 / q_{1}$. The yield surface, now accounting for damage, is expressed as

$$
\phi=\sigma_{*}-\sigma_{F}(p)
$$

and plastic flow is obtained using the normality rule as: $\underline{\varepsilon}_{p}=(1-f) \dot{p} \partial \sigma_{*} / \partial \underline{\sigma}$. The evolution of the porosity is derived from mass conservation as:

$$
\dot{f}=(1-f) \operatorname{trace}\left(\underline{\dot{\varepsilon}}_{p}\right)
$$

Damage nucleation is not used in this study as tests correspond to high stress triaxiality situations where void growth and coalescence are the only damage mechanism. Tuned model parameters (Shinohara et al., 2016) are reported in tab. 3. Note that the initial porosity, $f_{0}$, is very low which corresponds to modern high quality steels in which the sulfur content is very low. Values of parameters of $\alpha_{\mathrm{T}}, \alpha_{\mathrm{L}}$ and $\alpha_{\mathrm{S}}$ were slightly increased by the same factor $(4.8 \%)$ for the prestrain materials so as to obtain a better fit of the experiments as discussed in the following (section 6.1). Tuning was done by trial and error on NT and CT specimens. Details on the techniques used to perform the simulations are detailed in (Shinohara et al., 2016). In all cases, 8 nodes bricks with full integration (8 Gauss points) were used to perform the finite element (FE) simulations. To avoid pressure fluctuations within the elements, a selective integration technique was used (Hughes, 1980). Usual symmetry conditions were used so that $1 / 8$ of NT specimens and $1 / 4$ of CT specimens were meshed. The proposed model in absence of a regularization method is mesh size dependent. To obtain consistent results, a pragmatic solution consisting of using a fixed mesh size along the crack path is used (Rousselier, 1987; Liu et al., 1994). In this study, the element height in the direction perpendicular to the crack plane was fixed to $100 \mu \mathrm{m}$. Note that the model neglects kinematic hardening which exists in the investigated material (Shinohara et al., 2010). Incorporating kinematic damage in the GTN modeling framework is possible (Mear and Hutchinson, 1985; Besson and Guillemer-Neel, 2003; Morin et al., 2017) but remains difficult in particular if plastic anisotropy and failure anisotropy are to be accounted for.

\begin{tabular}{lccccccc}
\hline & $f_{0}$ & $q_{1}$ & $\alpha_{\mathrm{T}}$ & $\alpha_{\mathrm{L}}$ & $\alpha_{\mathrm{S}}$ & $f_{c}$ & $\delta$ \\
as received & $2.10^{-4}$ & 1.80 & 1.21 & 0.65 & 1.23 & 0.05 & 4.5 \\
prestrained & & & 1.27 & 0.68 & 1.29 & & \\
\hline
\end{tabular}

Table 3 Material parameters for the anisotropic GTN model

\section{Simulation of prestrain effects}

In this section, tests carried out on notched bars and CT specimens are simulated. Prestrain is accounted for by performing simulations of tensile tests up to the desired level $(2,4$ or $6 \%$ ). Computed state variables (porosity $f$ and cumulated plastic strain $p$ ) are then used as initial values for the simulation of test specimens machined in the prestrain material. Initial values for $p$ and $f$ are gathered in tab. 4 for the different prestrain levels. Note that porosity only slightly increases due to the low stress triaxiality (1/3) during prestraining. 


\begin{tabular}{ccccc}
\hline prestrain (\%) & 0 & 2 & 4 & 6 \\
\hline$p$ & 0. & $1.8010^{-2}$ & $3.8610^{-2}$ & $5.9010^{-2}$ \\
$f$ & $2.10^{-4}$ & $2.0410^{-4}$ & $2.0810^{-4}$ & $2.1210^{-4}$ \\
\hline
\end{tabular}

Table 4 Values of $p$ and $f$ after prestraining.

\subsection{Notched bars}

A comparison between experimental and simulated normalized force $\left(F / S_{0}\right)$ - diameter reduction $\left(\Delta \Phi_{\mathrm{S}} / \Phi_{0}\right)$ curves is shown in fig. 11 for $\mathrm{NT}_{2}$ specimens loaded along the $\mathrm{T}$ direction for all prestrain levels. The experimental trends are well reproduced by the simulations: increase of the maximum load with increasing prestrain, (ii) decrease of ductility marked by the sharp load drop with increasing prestrain, (iii) saturation of the effect of prestrain when the prestrain level reaches the necking strain.

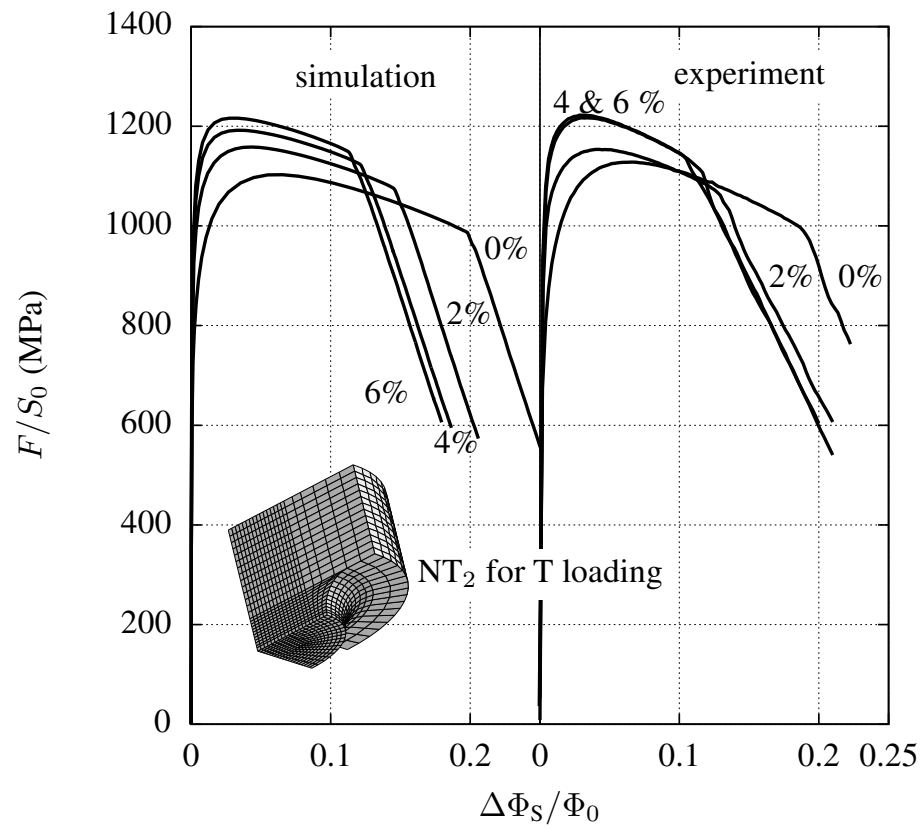

Fig. 11 Normalized force $\left(F / S_{0}\right)$ - diameter reduction $\left(\Delta \Phi_{\mathrm{S}} / \Phi_{0}\right)$ curves for $\mathrm{NT}_{2}$ specimens loaded along the $\mathrm{T}$ direction for various prestrain levels. curves

All notched bar specimens were also simulated. Fig. 12 shows computed ductilities as a function of prestrain level for both loading directions. Corresponding experimental data are shown in fig. 7. The main experimental trends are well reproduced. The model is able to correctly represent ductility anisotropy. The model also shows that prestrain effects tend to saturate when plastic prestrain is close to the necking strain. The fact that $\mathrm{NT}_{1}$ specimens may lead to larger ductilities than $\mathrm{NT}_{2}$ specimen is reproduced although overestimated for $\mathrm{T}$ loading. 


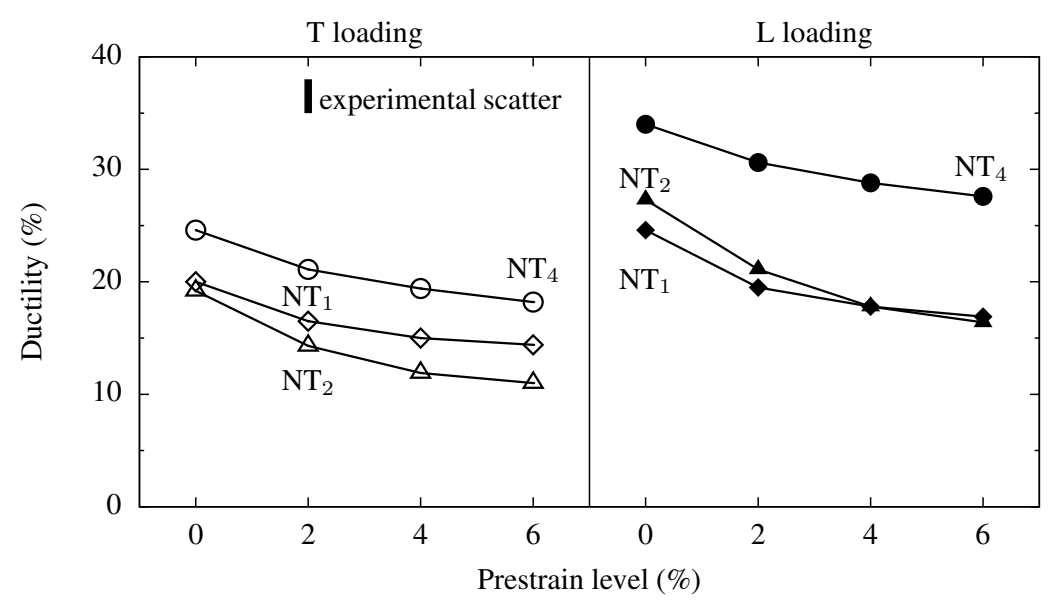

Fig. 12 Simulated ductilities for $\mathrm{T}$ and $\mathrm{L}$ loading for the different $\mathrm{NT}_{\chi}$ bars as a function of prestrain.

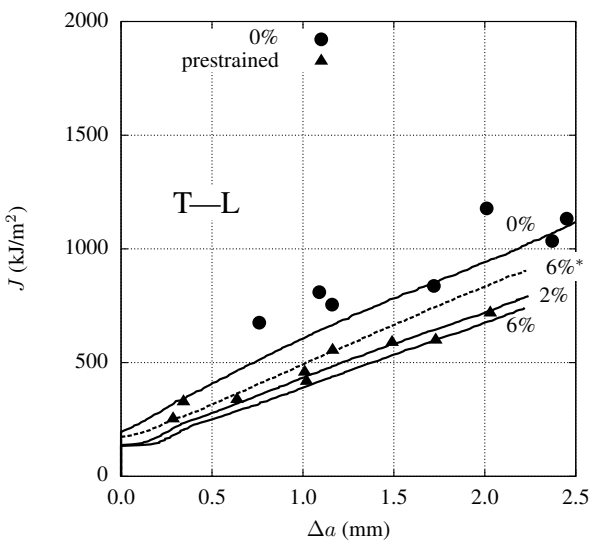

(a) $\mathrm{T}$-L loading

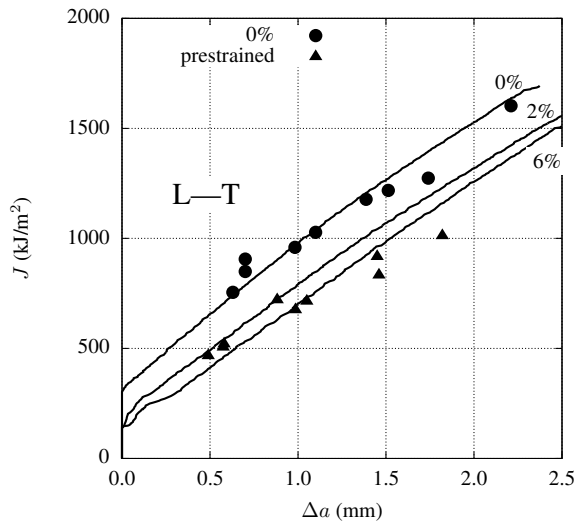

(b) L-T loading

Fig. 13 Simulated $J-\Delta a$ curves for $\mathrm{T}-\mathrm{L}$ (a) and $\mathrm{L}-\mathrm{T}$ (b) loading.

\subsection{Compact Tension specimens}

Simulated $J-\Delta a$ curves for both loading conditions are compared with experimental data points in fig. 13. As for NT specimens fracture anisotropy is well reproduced. The T- $\mathrm{L}$ loading case is shown in fig. 13-(a). R-curves for 0,2 and $6 \%$ prestrain are plotted. In agreement with experimental trends the difference between materials prestrained at 2 and $6 \%$ is very limited. The dashed curve referred to as $6 \%{ }^{*}$ corresponds to the simulation carried out using constant values for the $\alpha_{\mathrm{T}, \mathrm{L}, \mathrm{S}}$ coefficients. In that case, the effect of prestrain is underestimated. The $\mathrm{L}-\mathrm{T}$ loading case is shown in fig. 13-(b). Simulations for materials prestrained at 2 and $6 \%$ are again close to experimental results provided modified values for $\alpha_{\mathrm{T}, \mathrm{L}, \mathrm{S}}$ coefficients are used.

Fig. 14 shows a comparison of the observed and simulated crack fronts for a CT specimen loaded in the $\mathrm{T}-\mathrm{L}$ configuration and an imposed load-line displacement equal 


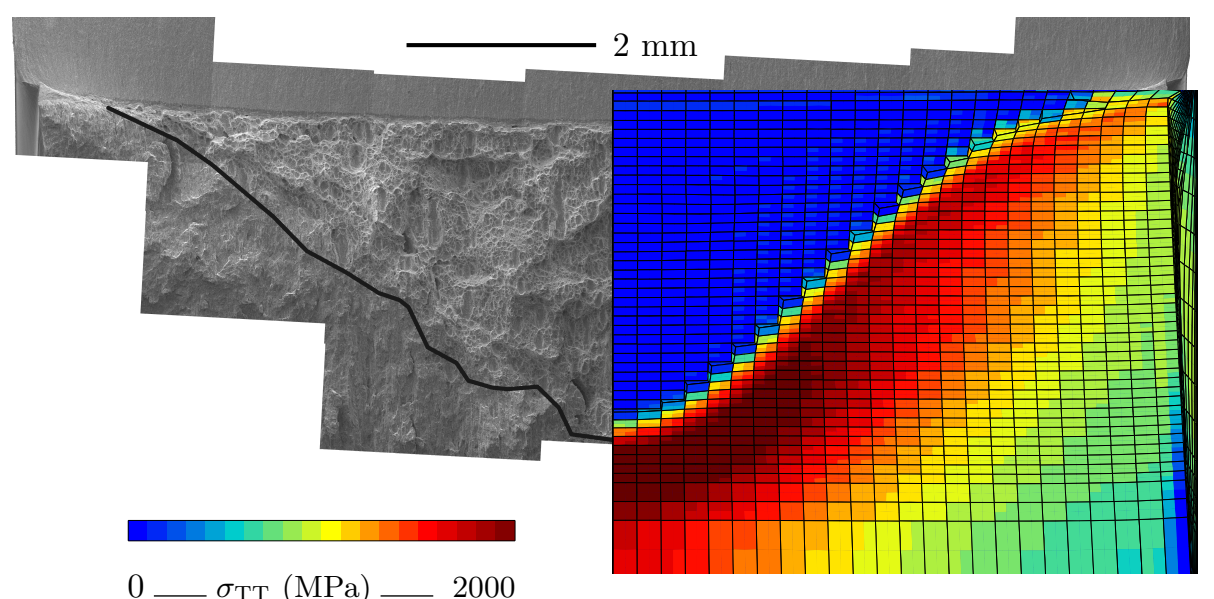

Fig. 14 Simulated and experimental crack advance: T-L loading, 6\% prestrain, Load-line displacement $1.75 \mathrm{~mm}$.

to $1.75 \mathrm{~mm}$. The contours indicate the opening stress ahead of the crack front. The blue area corresponds to the crack where the opening stresses are equal to 0 .

\section{Discussion: origin of the effect of prestrain on ductility and toughness}

The above reported simulations have shown that the effects of prestrain on ductility and toughness can be well reproduced using the finite element method. It is however necessary to slightly increase damage rate in prestrained materials to obtain a good correspondence. In this section, the origin of the effect of prestrain is discussed based on simulations using the proposed modeling of the material behavior.

\subsection{Effect of prestrain on void growth - Unit cell calculations}

Unit cell calculations (Koplik and Needleman, 1988) are powerful tools to numerically investigate void growth in porous solids and the effect of various parameters on ductile damage growth and coalescence. In this study, unit cell calculations similar to those reported in (Shinohara et al., 2016) were carried out for fixed macroscopic stress triaxialities. The main loading direction is the $\mathrm{T}$ direction and stresses along $\mathrm{L}$ and $\mathrm{S}$ directions are taken to be equal. The cell initial porosity corresponds to the inclusion volume fraction of the material, i.e. $f_{0}=2 \cdot 10^{-4}$. Three cases are compared. The first one corresponds to no prestrain $(0 \%)$. In the second case $(6 \%(\mathrm{p}))$, the value of the cumulated plastic strain is initialized to the value corresponding to a uniaxial loading (see tab. 4) but the shape of the unit cell as well as the initial porosity are kept unchanged. In the third case $(6 \%)$, prestraining of the unit cell is simulated so that it becomes slightly elongated. Triaxial loading is subsequently applied. In that case, the cell elongation is computed using the prestrained configuration as the reference configuration. Results for a stress triaxiality equal to 1.5 are reported in fig. 15-(a). It is shown that void growth tends to be slightly faster for cases corresponding 


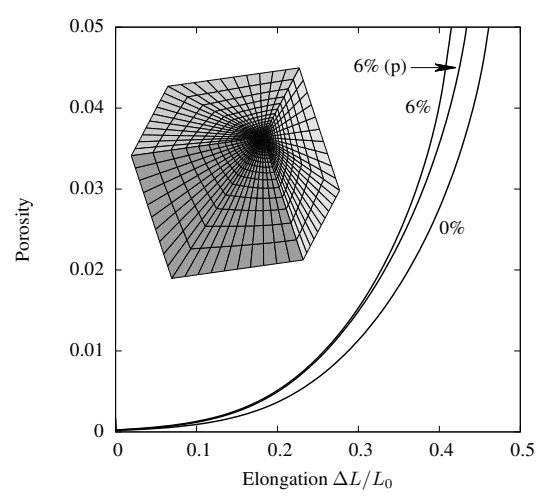

(a) Unit Cell

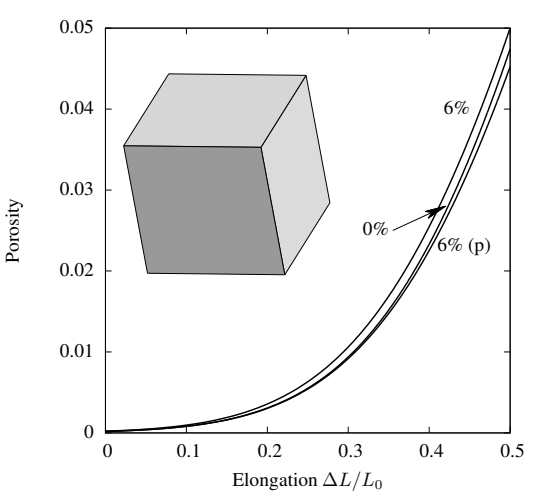

(b) GTN RVE

Fig. 15 Comparison of unit cell calculations (a) and simulations using one element together with the modified GTN model (b). Macroscopic stress triaxiality is equal to 1.5 ; the main loading direction is the T direction.

to prestraining compared to the un-prestrained case. The difference between the " $6 \%$ " and "6\%(p)" prestraining strategies remains very small although the former leads to a slightly faster growth.

Similar calculations were carried out using one element in which the material behavior is the modified GTN model presented above using $\alpha_{T}, \alpha_{L}$ and $\alpha_{S}$ coefficients for the asreceived material. Results are shown in fig. 15-(b). It can be concluded that prestrain hardly affects void growth in that case. Note that the growth kinetics differs from the results shown in fig. 15-(a) as the GTN coefficients were fitted on experimental results and not on the unit cell calculations.

It can therefore be concluded that prestrain favors void growth and that this effect is not represented by the GTN model. Modifying the GTN model parameters (i.e. $\alpha_{\mathrm{T}, \mathrm{L}, \mathrm{S}}$ coefficients in this study) allows this effect to be better reproduced. This is consistent with unit cell calculations performed in (Faleskog et al., 1998) which showed that GTN model parameters ( $q_{1}$ and $q_{2}$ in this study) depend on the hardening behavior of the material which is modified by prestraining. A possible solution could be to express the model parameters as functions of the instantaneous hardening exponent defined as: $n=\partial \log \left(\bar{\sigma}_{F}\right) / \partial \log (p)$.

\subsection{Effect of prestrain on stress state in structures}

Simple elasto-plastic simulations (i.e. without damage growth) of $\mathrm{NT}_{4}$ and CT specimens were carried out for different prestrain levels corresponding to the various values of $p$ listed in tab. 4 . These simualtions were post-processed to evaluate the "effective" stress triaxiality defined as:

$$
T_{*}=\frac{1}{3} \frac{\alpha_{\mathrm{T}} \sigma_{\mathrm{TT}}+\alpha_{\mathrm{L}} \sigma_{\mathrm{LL}}+\alpha_{\mathrm{S}} \sigma_{\mathrm{SS}}}{\sigma_{E}}
$$

$T_{*}$ is the driving force for damage in the proposed modified GTN model. It was evaluated at the center of the notch for the $\mathrm{NT}_{4}$ specimen (i.e. where the ductile crack initiates) and $10 \mathrm{~mm}$ from the initial crack tip at the center of the CT specimen. 


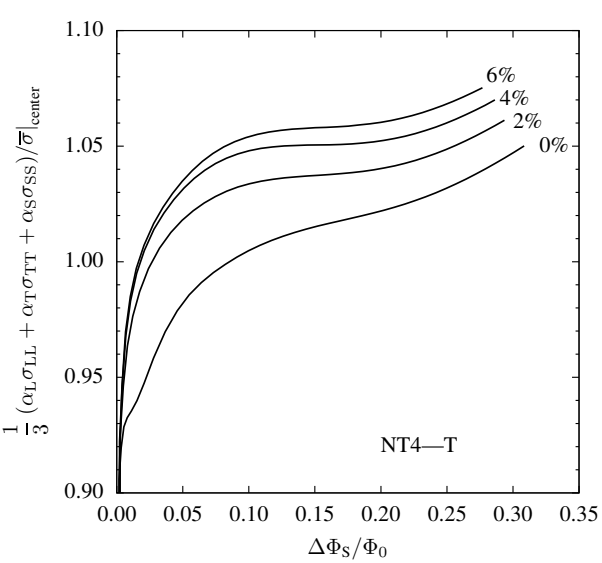

(a)

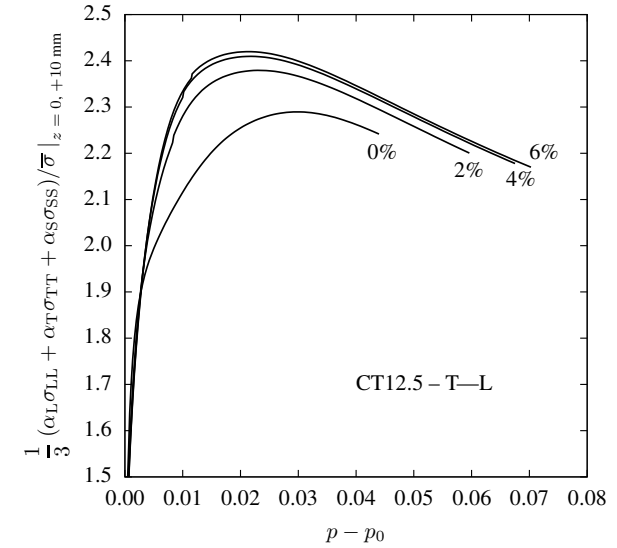

(b)

Fig. 16 Effect of prestrain on stress distribution: (a) Evolution of $T_{*}$ at the center of a $\mathrm{NT}_{4}$ specimen for various prestrain levels as a function of relative diameter contraction along the $\mathrm{S}$ direction. (b) Evolution of $T_{*}$ for various prestrain levels at the center of a CT specimen in an element $10 \mathrm{~mm}$ from the initial crack tip as a function of plastic strain increase at the same location.

Fig. 16-(a) displays results for the $\mathrm{NT}_{4}$ specimen. $T_{*}$ is plotted as a function of the relative diameter contraction along the $\mathrm{S}$ direction. It can be observed that triaxiality increases with increasing level of prestrain with a much more pronounced effect between $0 \%$ and $2 \%$ than between $4 \%$ and $6 \%$. This effect is linked to the different hardening behavior of the prestrained materials which affects stress/strain distribution within the notch. Higher values for $T_{*}$ will indeed cause earlier failure with increasing prestrain levels.

Fig. 16-(b) displays results for the CT specimen. $T_{*}$ is plotted as a function of the local cumulated plastic strain increase $p-p_{0}$ where $p_{0}$ is the prestrain level. Calculations were conducted up to a load-line displacement equal to $2 \mathrm{~mm}$. As for the $\mathrm{NT}_{4}$ specimen, $T_{*}$ increases with increasing prestrain level. The plastic strain level reached at the end of loading also increases with prestrain. Both effects promote ductile damage growth. In agreement with results for the $\mathrm{NT}_{4}$ specimen, the effect is more pronounced between $0 \%$ and $2 \%$ than between $4 \%$ and $6 \%$.

Results on both $\mathrm{NT}_{4}$ and CT specimens are consistent. They show that loss of workhardening capacity due to prestrain affects stress/strain distribution in notches and at crack tips. The effect is such that local triaxiality levels as well as plastic strains increase leading to earlier failure. This effect constitutes the second cause for the observed decrease of ductility and toughness. Note that considering the usual stress triaxiality $\frac{1}{3} \sigma_{k k} / \sigma_{\text {eq }}$ or $\frac{1}{3} \sigma_{k k} / \sigma_{E}$ leads to the same conclusions.

\subsection{Respective effects of pre-hardening and pre-damage}

Prestrain causes both pre-hardening and pre-damage as indicated in tab. 4. Using the proposed model it becomes possible to distinguish the role of both effects on ductility and toughness decrease. In the case where pre-hardening is studied, $f_{g}$ is set to its initial value (i.e. $2.10^{-4}$ ) and values for $p$ listed in tab. 4 are used. When pre-damage only is studied, $p$ 


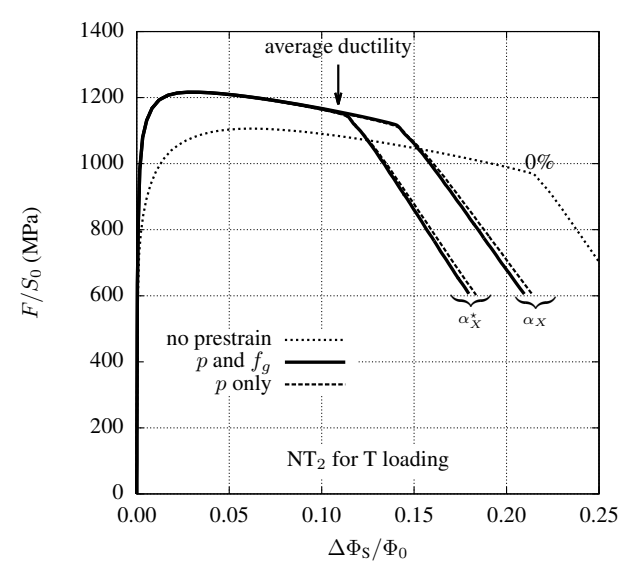

(a) Effect of pre-hardening

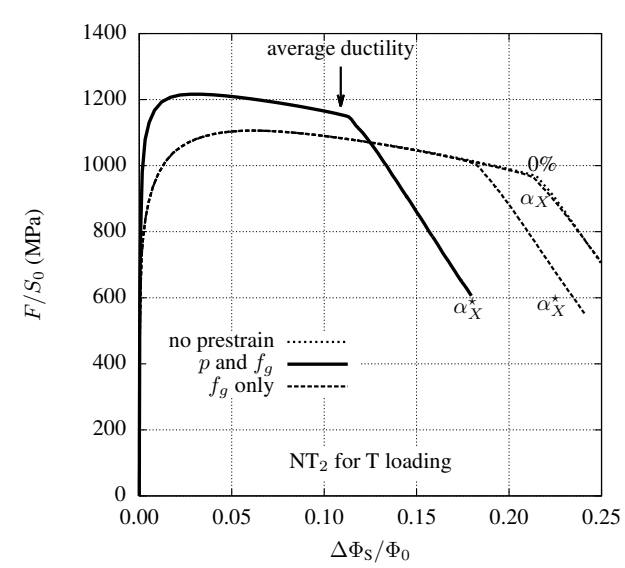

(b) Effect of pre-damage

Fig. 17 Simulation of a $\mathrm{NT}_{2}$ specimen for a prestrain level of 6\%: (a) Effect of pre-hardening (b) Effect of pre-damage.

is set to 0 and values for $f_{g}$ in tab. 4 are used. Note that porosity increase during prestrain is very small due to the low triaxiality so that the effect of pre-damage is indeed likely to be very limited. The study is carried out in the case of a $6 \%$ prestrained material using a $\mathrm{NT}_{2}$ specimen loaded along the $\mathrm{T}$ direction. Conclusions are similar for all notched bars as well as CT specimens.

The effect of pre-hardening is shown in fig. 17-a. Accounting for prestrain allows describing load increase. Use of modified values for $\alpha_{\mathrm{T}, \mathrm{L}, \mathrm{S}}\left(\alpha_{X}^{*}\right.$ in fig. 17) leads to lower ductilities than using values for the as-received material ( $\alpha_{X}$ in fig. 17). These ductilities are closer to the experiments. A similar trend can be seen in fig. 13-a where $J-\Delta a$ curves are compared using original $(6 \%)$ and modified $\left(6 \%^{*}\right)$ values for the $\alpha_{\mathrm{T}, \mathrm{L}, \mathrm{S}}$ parameters. Calculations were carried out with both $p$ and $f_{g}$ being initialized to values after prestraining (solid lines $/ p$ and $f_{g}$ in fig. 17) and with $p$ being initialized and $f_{g}$ set to its initial value, i.e. $2.10^{-4}$ (dashed lines/ $p$ only in fig. 17). The difference between both sets is very limited showing that the effect of pre-damage is negligible.

In fig. 17-b simulations are carried out assuming no pre-hardening and pre-damage only. In that case, load increase cannot indeed be represented. Calculations using constant values for $\alpha_{\mathrm{T}, \mathrm{L}, \mathrm{S}}$ are very close to the simulation corresponding to the as-received material $(0 \%)$ showing again that the effect of pre-damage can be neglected. Using modified values for $\alpha_{\mathrm{T}, \mathrm{L}, \mathrm{S}}\left(\alpha_{X}^{*}\right.$ in fig. 17) results in a decrease of ductility which however remains underestimated compared to experiments and the simulation including the effect of pre-hardening.

It can therefore be concluded that the decrease in toughness and ductility caused by prestraining is only caused by pre-hardening and that the effect of pre-damage can be neglected. This conclusion is indeed only valid for prestrain levels less than $6 \%$ performed for low stress triaxialities. Higher prestrain levels could indeed lead to pre-damage in particular if reached under high triaxiality. 


\section{Conclusions}

Effect of tensile prestraining on both ductility and toughness was investigated on an API grade X100 line pipe steel. Prestraining was limited to $6 \%$ which corresponds to the necking strain of the material. Experiments show a reduction of both ductility and toughness which is more pronounced for low prestrain levels $(0 \rightarrow 2 \%)$. Although a deleterious effect of prestrain is usually observed (Sivaprasad et al., 2000; Enami, 2005b; Baek et al., 2010; Kamaya, 2012), the saturation effect was not observed in previous studies which were all dealing with lower grade line pipe steels (X60-X70) or construction steels. Larger effects of prestrain could possibly be observed for prestrain levels above the necking strain.

In order to interpret the experimental findings, experiments were simulated using the model proposed by Shinohara et al. (2016) fitted on the as received material. It is shown that experimental results can be reproduced provided some of the damage model parameters are modified so as to slightly increase damage rates in the case of prestrained materials. This corresponds to the decrease of the hardening exponent $n$ which according to the results of Faleskog et al. (1998) could lead to higher damage rates. A possible future solution, could be to express some of the model parameters as functions of the instantaneous hardening exponent $\partial \log \left(\bar{\sigma}_{F}\right) / \partial \log (p)$ which can be expressed as a function of the cumulated plastic strain $p$.

To elucidate the origin of prestrain, unit cell calculations as well as a parametric study allowing for the separation of the effects of pre-hardening and pre-damage were conducted. Based on these investigations, it was concluded that pre-hardening is the only cause for the decrease of mechanical properties whereas the effect of pre-damage is negligible. This conclusion is indeed only valid for the limited investigated prestrain levels. Much larger prestrain levels could, for instance, favor void nucleation on carbides (Tanguy et al., 2008) and further reduce properties. Furthermore prestraining and associated decrease of work hardening have two effects which both lead to a drop in ductility and toughness: low hardening (i) favors void growth, (ii) modifies stress/strain distribution in part so as to increase local stress triaxiality. The first effect is represented by modifying material damage parameter. The second effect is automatically accounted for when performing finite element simulations. These conclusions are indeed only valid for highly ductile materials for which failure is controlled by void growth and coalescence as in the case of modern linepipe steels. The effect of prestrain could be larger and/or different in the following cases: (i) strain nucleation plays an important role in the damage process (ii) stress triaxiality is low so that growth is limited, (iii) ductility is low.

Acknowledgements:The authors would like to acknowledge Nippon Steel Corporation (now Nippon Steel \& Sumitomo Metal Corporation) for financial support to this study. 


\section{References}

Alinaghian, Y., Asadi, M., and Weck, A. (2014). Effect of pre-strain and work hardening rate on void growth and coalescence in AA5052. Int. J. Plasticity, 53:193-205.

Asahi, H., Hara, T., Tsuru, E., and Morimoto, H. (2009). Development and commercialiation of high-strength linepipe. In Proc. pipeline technology conference, Ostend 12-14 October 2009.

ASTM-1820 (2008). Standard test method for measurement of fracture toughness. Technical report.

Baek, J.-H., Kim, Y.-P., Kim, C., Kim, W., and Seok, C. (2010). Effects of pre-strain on the mechanical properties of API 5L X65 pipe. Mater. Sci. Engng A, 527(6):1473-1479.

Barlat, F., Aretz, H., Yoon, J., Karabin, M., Brem, J., and Dick, R. (2005). Linear transfomation-based anisotropic yield functions. Int. J. Plasticity, 21(5):1009-1039.

Barlat, F., Lege, D., and Brem, J. (1991). A six-component yield function for anisotropic materials. Int. J. Plasticity, 7:693-712.

Basu, S. and Benzerga, A. (2015). On the path-dependence of the fracture locus in ductile materials: Experiments. Int. J. Solids Structures, 71:79-90.

Besson, J. (2009). Damage of ductile materials deforming under multiple plastic or viscoplastic mechanisms. Int. J. Plasticity, 25:2204-2221.

Besson, J. and Guillemer-Neel, C. (2003). An extension of the Green and Gurson models to kinematic hardening. Mech. Mater, 35:1-18.

Besson, J., Steglich, D., and Brocks, W. (2001). Modeling of crack growth in round bars and plane strain specimens. Int. J. Solids Structures, 38(46-47):8259-8284.

Bron, F. and Besson, J. (2004). A yield function for anisotropic materials. Application to aluminium alloys. Int. J. Plasticity, 20:937-963.

Chae, D., Bandstra, J., and Koss, D. (2000). The effect of pre-strain and strain-path changes on ductile fracture: experiment and computational modeling. Mater. Sci. Engng A, A285:165-171.

Eikrem, P., Zhang, Z., Østby, E., and Nyhus, B. (2008). Numerical study on the effect of prestrain history on ductile fracture resistance by using the complete Gurson model. Eng. Fract. Mech., 75:4568-4582.

Eikrem, P. A., Zhang, Z., and Nyhus, B. (2007). Effect of plastic prestrain on the crack tip constraint of pipeline steels. Int. J. of Pressure Vessels and Piping, 84(12):708-715.

El-Fadaly, M., El-Sarrage, T., Eleiche, A., and Dahl, W. (1995). Fracture toughness of $20 \mathrm{MnMoNi} 55$ steel at different temperatures as affected by room-temperature predeformation. J. Mater. Processing Technol., 54:159-165.

Enami, K. (2005a). Ductile crack initiation behavior in steels with compressive prestrain. $J$. Mar. Sci. Technol., 10:10-41.

Enami, K. (2005b). The effects of compressive and tensile prestrain on ductile fracture initiation in steels. Eng. Fract. Mech., 72(7):1089-1105.

Faleskog, J., Gao, X., and Shih, C. (1998). Cell model for nonlinear fracture analysis - I. Micromechanics calibration. Int. J. Frac., 89:355-373.

Hill, R. (1950). The mathematical theory of plasticity. Clarendon Press, Oxford.

Hughes, T. (1980). Generalization of selective integration procedures to anisotropic and non linear media. Int. J. Numer. Meth. Engng, 15:1413-1418.

Kamaya, M. (2012). A stress-based criterion for ductile crack initiation of pre-strained carbon steel. Eng. Fract. Mech., 96:461-479.

Karafillis, A. and Boyce, M. (1993). A general anisotropic yield criterion using bounds and a transformation weighting tensor. J. Mech. Phys. Solids, 41:1859-1886. 
Koplik, J. and Needleman, A. (1988). Void growth and coalescence in porous plastic solids. Int. J. Solids Structures, 24(8):835-853.

Lillig, D. (2008). The first (2007) isope strain-based design symposium - a review. In Proc. 18th international offshore and polar engineering (ISOPE) conference, Vancouver 6-11 july 2008.

Liu, Y., Murakami, S., and Kanagawa, Y. (1994). Mesh-dependence and stress singularity in finite element analysis of creep crack growth by continuum damage mechanics approach. Eur. J. Mech./A, 13A(3):395-417.

Mackenzie, A., Hancock, J., and Brown, D. (1977). On the influence of state of stress on ductile failure initiation in high strength steels. Eng. Fract. Mech., 9:167-188.

Mear, M. and Hutchinson, J. (1985). Influence of yield surface curvature on flow localization in dilatant plasticity. Mech. Mater., 4:395-407.

Morgeneyer, T., Besson, J., Proudhon, H., Starink, M., and Sinclair, I. (2009). Experimental and numerical analysis of toughness anisotropy in AA2139 al alloy sheet. Acta Mater., 57(13):3902-3915.

Morin, L., Michel, J.-C., and Leblond, J.-B. (2017). A Gurson-type layer model for ductile porous solids with isotropic and kinematic hardening. Int. J. Solids Structures, 118:167178.

Pardoen, T. and Hutchinson, J. (2000). An extended model for void growth and coalescence. J. Mech. Phys. Solids, 48(12):2467-2512.

Rivalin, F., Besson, J., Pineau, A., and Di Fant, M. (2000). Ductile tearing of pipelinesteel wide plates - II.: Modeling of in-plane crack propagation. Eng. Fract. Mech., 68(3):347-364.

Rousselier, G. (1987). Ductile fracture models and their potential in local approach of fracture. Nucl. Eng. Des., 105:97-111.

Shinohara, Y., Besson, J., and Madi, Y. (2012). Anisotropic damage behavior in highstrength line pipe steels. Int. J. Offshore Polar Eng., 22(1):83-89.

Shinohara, Y., Madi, Y., and Besson, J. (2010). A combined phenomenological model for the representation of anisotropic hardening behavior in high strength steel line pipes. Eur. J. Mech./A, 29(6):917-927.

Shinohara, Y., Madi, Y., and Besson, J. (2016). Anisotropic ductile failure of a high-strength line pipe steel. Int. J. Frac., 197:127-145.

Shinohara, Y., Tsuru, E., Asahi, H., Hara, T., Terada, Y., Doi, N., Ayukawa, N., and Murata, M. (2008). Development of high-strength steel line pipe for SBD applications. Int. J. of offshore and polar engineering, 18(3):220-225.

Sivaprasad, S., Tarafder, S., Ranganath, V., and Ray, K. (2000). Effect of prestrain on fracture toughness of hsla steels. Mater. Sci. Engng A, 284:195-201.

Song, W., Liu, X., Berto, F., Xu, J., and Fang, H. (2017). Numerical simulation of prestrain history effect on ductile crack growth in mismatched welded joints. Fatigue and Fract. Engng Mater. Struct., 40(9):1472-1483.

Tanguy, B., Luu, T., Perrin, G., Pineau, A., and Besson, J. (2008). Plastic and damage behavior of a high strength X100 pipeline steel: experiments and modelling. Int. J. of Pressure Vessels and Piping, 85(5):322-335.

Thomas, N., Basu, S., and Benzerga, A. (2016). On fracture loci of ductile materials under non-proportional loading. Int. J. Mech. Sci., 117:135-151.

Thomason, P. F. (1985a). A three-dimensional model for ductile fracture by the growth and coalescence of microvoids. Acta Metall., 33(6):1087-1095.

Thomason, P. F. (1985b). Three-dimensional models for the plastic limit-loads at incipient failure of the intervoid matrix in ductile porous solids. Acta Metall., 33(6):1079-1085. 
Tkaczyk, T., O’Dowd, N., and Nikbin, K. (2011). The effect of prestrain on ductile fracture toughness of reeled pipeline steels. J. Pressure Vessel Technol., 133.

Tsuru, E., Shinohara, Y., and Asahi, H. (2008). Evaluation precept for buckling resistance of high-strength uoe line pipes used in strainbased design SBD applications. Int. J. of offshore and polar engineering, 18(3):176-182.

Tvergaard, V. and Needleman, A. (1984). Analysis of the cup-cone fracture in a round tensile bar. Acta Metall., 32:157-169.

Yoo, J.-Y., Ahn, S.-S., Seo, D.-H., Song, W.-H., and Kang, K.-B. (2011). New Development of High Grade X80 to X120 Pipeline Steels. Mater. Manuf. Process., 26(1):154-160.

Zhang, S., Leotoing, L., Guines, D., Thuillier, S., and Zang, S. (2014). Calibration of anisotropic yield criterion with conventional tests or biaxial test. Int. J. Mech. Sci., 85:142-151.

Zhang, Z. and Skallerud, B. (2010). Void coalescence with and without prestrain history. Int. J. Damage Mech., 19:153-174. 


\section{List of Figures}

1 Large tensile specimen for prestraining (dimensions in $\mathrm{mm}$ ). The gray area indicates the zone where prestrain is homogeneous. . . . . . . . . . 4

2 Test specimens: smooth tensile bar, axisymmetric notched bars. . . . . . . . 4

3 Nominal stress $\left(F / S_{0}\right)$ as a function of strain for T, L and D loading directions for the different prestrain levels. . . . . . . . . . . . .

4 Experimental normalized force $\left(F / S_{0}\right)$ vs. relative diameter reduction $\left(\Delta \Phi_{\mathrm{S}} / \Phi_{0}\right)$ curves for L loading and $2 \%$ prestrain for $\mathrm{NT}_{4}, \mathrm{NT}_{2}$ and $\mathrm{NT}_{1}$

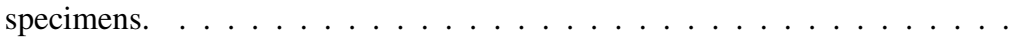

5 Experimental normalized force $\left(F / S_{0}\right)$ vs. relative diameter reduction $\left(\Delta \Phi_{\mathrm{S}} / \Phi_{0}\right)$ curves for $4 \%$ prestrain for $\mathrm{NT}_{2}$ and $\mathrm{NT}_{1}$ specimens tested along $\mathrm{L}$ and $\mathrm{T}$ directions. . . . . . . . . . . . . . . .

6 Experimental normalized force $\left(F / S_{0}\right)$ vs. relative diameter reduction $\left(\Delta \Phi_{\mathrm{S}} / \Phi_{0}\right)$ curves for $\mathrm{NT}_{2}$ specimens tested along $\mathrm{L}$ and $\mathrm{T}$ directions for various prestrain levels. . . . . . . . . . . . . . . . .

7 Experimental ductility $\left(\Delta \Phi_{S} /\left.\Phi_{0}\right|_{c}\right)$ as a function of prestrain. T-loading (open symbols) and L-loading (closed symbols). . . . . . . . . . . . . .

8 Experimental area reduction $(Z)$ as a function of prestrain. T-loading (open symbols) and L-loading (closed symbols). . . . . . . . . . . . . . . . .

$9 J-\Delta a$ curves for all prestrain levels: (a) $\mathrm{L}-\mathrm{T}$ configuration, (b) $\mathrm{T}-\mathrm{L}$ configuration. Solid lines correspond to the fit of the experimental data as $J=J_{0}+T \Delta a$ for each testing condition (configuration and prestrain level).

10 Fractography of $\mathrm{NT}_{4}$ specimens for the as-received material (a) and 6\% prestrained material (b). In both cases, the fracture surface mainly consists in primary dimples ; secondary dimples can also be observed. . . . . . . . .

11 Normalized force $\left(F / S_{0}\right)$ - diameter reduction $\left(\Delta \Phi_{\mathrm{S}} / \Phi_{0}\right)$ curves for $\mathrm{NT}_{2}$ specimens loaded along the $\mathrm{T}$ direction for various prestrain levels. curves .

12 Simulated ductilities for $\mathrm{T}$ and $\mathrm{L}$ loading for the different $\mathrm{NT}_{\chi}$ bars as a function of prestrain. . . . . . . . . . . . . . . . 15

13 Simulated $J-\Delta a$ curves for $\mathrm{T}-\mathrm{L}$ (a) and $\mathrm{L}-\mathrm{T}$ (b) loading. . . . . . . . . 15

14 Simulated and experimental crack advance: $\mathrm{T}-\mathrm{L}$ loading, 6\% prestrain,

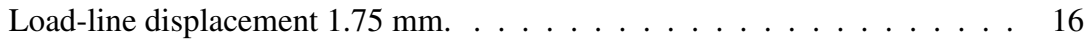

15 Comparison of unit cell calculations (a) and simulations using one element together with the modified GTN model (b). Macroscopic stress triaxiality is equal to 1.5 ; the main loading direction is the $\mathrm{T}$ direction. . . . . . . . .

16 Effect of prestrain on stress distribution: (a) Evolution of $T_{*}$ at the center of a $\mathrm{NT}_{4}$ specimen for various prestrain levels as a function of relative diameter contraction along the $\mathrm{S}$ direction. (b) Evolution of $T_{*}$ for various prestrain levels at the center of a CT specimen in an element $10 \mathrm{~mm}$ from the initial crack tip as a function of plastic strain increase at the same location. . . . . 18

17 Simulation of a $\mathrm{NT}_{2}$ specimen for a prestrain level of 6\%: (a) Effect of prehardening (b) Effect of pre-damage. . . . . . . . . . . . . . . . . . 19

\section{List of Tables}

1 Chemical composition of the used steel (weight $\%$ ). . . . . . . . . . . 
2 Values of $J$ at initiation $\left(J_{0}\right)$ and tearing modulus $T$ for the as-received and prestrained materials for $\mathrm{T}-\mathrm{L}$ and $\mathrm{L}-\mathrm{T}$ loading. Average values are given for the prestrained materials as individual values are very close. Average values for all materials (as-received and prestrain) are also indicated for the tearing modulus which is hardly affected by prestrain. . . . . . . . . 10

3 Material parameters for the anisotropic GTN model . . . . . . . . . . . . . 13

$4 \quad$ Values of $p$ and $f$ after prestraining. . . . . . . . . . . . . . . 14 